Research Article

\title{
In the labyrinth of e-health: exploring attitudes towards e-health in greece
}

\begin{abstract}
Background: Attitudes towards e-Health have been little investigated in Greece in the general population as well as in healthcare students and professionals, while at the same time undergraduate curricula with focus on e-Health are entirely missing.

Aims: To explore attitudes towards e-Health among students, doctors and laypeople in Greece across several demographic variables.

Methods: Three hundred eighty participants (180 first-year healthcare university students from various faculties including medicine, pharmacy, biology, nursing, physiotherapy, midwifery, healthcare engineers, 100 medical doctors of various specialties working in hospitals and private practice, and 100 laypeople) living in different Greek geographical areas completed a modified version of the Attitude Towards e-Health questionnaire along with a detailed demographics questionnaire.

Results: Results revealed that the three groups showed statistically significant differences for all aspects of e-Health attitudes, reporting more negative attitudes, regardless of their education, gender and age when compared with similar findings from other countries. In addition, the majority of the participants reported lack of educational experience regarding e-Health.

Conclusion: Present findings showed that the current efforts and relevant initiatives by the Greek State, private institutions and the Greek Medical Societies should refocus and emphasize on e-Health education programs concerning the dissemination of relevant scientific information on potential benefits and challenges in providing and accessing e-Health, either as a provider or as a consumer. Future research should further investigate in more depth the complex influence of additional social and/or psychological factors for the reported differences.
\end{abstract}

Keywords: e-health, attitudes, students, doctors, laypeople
Volume 8 Issue 2 - 2017

Vaitsa Giannouli, Thomas Hyphantis

Department of Psychiatry, University of loannina, Greece

Correspondence: Thomas Hyphantis, Department of Psychiatry, Faculty of Medicine, School of Health Sciences, University of loannina, loannina 45। I0, Greece, Email tyfantis@cc.uoi.gr

Received: August 28, 2017 | Published: September 06, 2017

\section{Introduction}

e-Health has been recognized as a rapidly evolving component of healthcare in the 21 st century. e-Health has various definitions, and one of the most widespread is the one reported by the World Health Organization:1 'the transfer of health resources and healthcare by electronic means... It encompasses the delivery of health information for health professionals and health consumers, through the Internet and communications'. Although numerous studies in different countries have examined e-Health and the influence that literacy may have on relevant attitudes ${ }^{2-4}$ as well as the cognitive (e.g. perceived ability) and emotional factors (e.g. confidence) that may influence these attitudes in healthcare professionals ${ }^{5}$ still there is little systematic research examining healthcare students, professionals and laypeople attitudes towards e-Health in Greece. ${ }^{6}$ The aim of this study focuses on the question 'What are the attitudes towards e-Health in Greek students, doctors and laypeople?'. More specifically, given the importance of the influence of demographic factors on attitudes towards eHealth, ${ }^{7-10}$ a hypothesis that is tested here examines whether age, education and gender differentiate these attitudes between individuals.

\section{Methods}

Three hundred eighty participants, including one hundred eighty first-year healthcare university students from various faculties including medicine, pharmacy, biology, nursing, physiotherapy, midwifery, healthcare engineers ( 72 male, 108 female; Mean age =
$19.01, \mathrm{SD}=.074)$, one hundred medical doctors of various specialties working in hospitals and private practice (64 male, 46 female; Mean age $=39.32, \mathrm{SD}=8.73$; Mean education $=18.00, \mathrm{SD}=.001)$, and one hundred laypeople (66 male, 34 female; Mean age $=54.65, \mathrm{SD}=$ 10.23; Mean education $=13.05, \mathrm{SD}=3.75$ ) living in different Greek geographical areas, completed a modified version of the Attitude Towards e-Health questionnaire along with a detailed demographics questionnaire. The samples had to have at least three years of experience with computers and internet applications in order to avoid any influences of lack of computer literacy in the reported attitudes. The participants were selected based on two inclusion criteria:

a. Participants were native Greek speakers living in Greece more than a decade.

b. Had no past or current psychiatric diagnosis or cognitive deficits.

The participants' attitudes towards e-Health were measured with a modified 4-point Likert scale version of the "efficiency to ICT in care' scale of the Information Technology Attitude Scales for Health (ITASH). This questionnaire containing four points from $1=$ strongly disagree to $4=$ strongly agree, was based on the scale introduced by Ward et al. ${ }^{11}$. Sixteen items were presented and participants had to answer in a paper-and-pencil way, with a total score ranging from a minimum of 16 points to a maximum of 64 points. The Cronbach's alpha for the whole sample was high for the negative statements of the questionnaire about e-Health $(\alpha=.913)$ and acceptable for the positive statements of the questionnaire about e-Health $(\alpha=.785)$. 
Table I First-year students, doctors and laypeople scores on attitude towards e-Health questionnaire

\begin{tabular}{|c|c|c|c|c|}
\hline Items of the Questionnaire & $\begin{array}{l}\text { Students } \\
\text { Mean (SD) }\end{array}$ & $\begin{array}{l}\text { Doctors } \\
\text { Mean (SD) }\end{array}$ & $\begin{array}{l}\text { Lay People } \\
\text { Mean(SD) }\end{array}$ & P-Value \\
\hline $\begin{array}{l}\text { Engaging in eHealth } \\
\text { will improve patient/client health. }\end{array}$ & $2.43(1.15)$ & $2.30(.77)$ & $\mathrm{I} .43(.64)$ & $<.001$ \\
\hline $\begin{array}{l}\text { The information that I will } \\
\text { get from electronic health records } \\
\text { will help give better care to patients. }\end{array}$ & 2.35 (1.09) & 2.01 (.88) & $\mathrm{I} .46(.6 \mathrm{I})$ & $<.001$ \\
\hline $\begin{array}{l}\text { Using ICT will make the communication with other } \\
\text { health professionals faster. }\end{array}$ & $2.33(1.04)$ & $2.36(.86)$ & I.72 (.78) & $<.001$ \\
\hline $\begin{array}{l}\text { I worry that the use of eHealth } \\
\text { applications in healthcare delivery will } \\
\text { undermine patient confidentiality. }\end{array}$ & $1.99(.86)$ & $2.49(.55)$ & $2.78(.68)$ & $<.001$ \\
\hline $\begin{array}{l}\text { I believe that eHealth will help the } \\
\text { delivery of individualised care. }\end{array}$ & $2.26(1.23)$ & $\mathrm{I} .57(.8 \mathrm{I})$ & $1.50(.80)$ & $<.001$ \\
\hline $\begin{array}{l}\text { Using ICT will make communication with } \\
\text { other health professionals less reliable. }\end{array}$ & $\mathrm{I} .86(.77)$ & $2.80(.65)$ & $2.68(.48)$ & $<.001$ \\
\hline $\begin{array}{l}\text { The cost of implementing eHealth } \\
\text { will be better used to employ more staff. }\end{array}$ & $1.91(.70)$ & $2.89(.64)$ & $2.76(.66)$ & $<.001$ \\
\hline $\begin{array}{l}\text { The time that a doctor spends with } \\
\text { patients will reduce because of the time } \\
\text { that they spend working with eHealth tools. }\end{array}$ & $1.93(.73)$ & $3.07(.82)$ & $2.88(.45)$ & $<.001$ \\
\hline $\begin{array}{l}\text { I think we are in danger of letting } \\
\text { eHealth take over traditional health } \\
\text { practices. }\end{array}$ & $1.78(.92)$ & $2.93(.78)$ & $3.20(.87)$ & $<.001$ \\
\hline $\begin{array}{l}\text { eHealth will help to improve the } \\
\text { way healthcare is delivered. }\end{array}$ & $2.01(1.06)$ & $2.12(1.22)$ & I.3I (.60) & $<.001$ \\
\hline $\begin{array}{l}\text { The speed with which healthcare } \\
\text { experts are able to access information } \\
\text { using eHealth applications will help } \\
\text { them give better care to patients. }\end{array}$ & $2.4 \mathrm{I}(.98)$ & $1.39(.62)$ & $1.69(.90)$ & $<.001$ \\
\hline $\begin{array}{l}\text { Time spent on eHealth will be out } \\
\text { of proportion to its benefits. }\end{array}$ & $1.96(.89)$ & $3.35(.77)$ & $3.14(.87)$ & $<.001$ \\
\hline $\begin{array}{l}\text { Use of electronic health records } \\
\text { will be more of a hindrance than a help } \\
\text { to patient care. }\end{array}$ & $1.90(.76)$ & $2.72(.66)$ & $2.68(1.04)$ & $<.001$ \\
\hline $\begin{array}{l}\text { I feel that there are too many } \\
\text { eHealth devices around now. }\end{array}$ & $2.15(.91)$ & $2.74(.5 \mathrm{I})$ & $2.72(.52)$ & $<.001$ \\
\hline $\begin{array}{l}\text { Engaging in eHealth will make } \\
\text { healthcare staff less productive. }\end{array}$ & I.78 (.69) & $2.79(.74)$ & $2.70(.57)$ & $<.001$ \\
\hline $\begin{array}{l}\text { Engaging in eHealth will be more } \\
\text { trouble than it will worth. }\end{array}$ & $1.91(.81)$ & $3.00(.60)$ & $3.05(.69)$ & $<.001$ \\
\hline
\end{tabular}

\section{Results}

Statistically significant differences were found between the three groups using three-way analysis of variance. There was a statistically main effect between the scores of ITASH for the group (students, doctors, laypeople) regarding question $1[\mathrm{~F}(2,377)=37.219, \mathrm{p}$ $<.001$, effect size was large (eta squared $=0.16$ )], for question 2 $[\mathrm{F}(2,377)=27.892, \mathrm{p}<.001$, effect size was large (eta squared $=$ $0.12)]$, for question $3[\mathrm{~F}(2,380)=16.095, \mathrm{p}<.001$, effect size was medium (eta squared $=0.07)]$, for question $4[\mathrm{~F}(2,378)=28.215$, $\mathrm{p}<.001$, effect size was large (eta squared $=0.16$ )], for question 5 $[\mathrm{F}(2,377)=23.532, \mathrm{p}<.001$, effect size was large (eta squared $=$ $0.11)]$, for question $6[\mathrm{~F}(2,377)=80.415, \mathrm{p}<.001$, effect size was large (eta squared $=0.29)]$, for question $7[\mathrm{~F}(2,377)=87.467, \mathrm{p}<$. 001 , effect size was large (eta squared $=0.31)]$, for question $8[\mathrm{~F}(2$, $378)=107.266, \mathrm{p}<.001$, effect size was large $($ eta squared $=0.36)]$, for question $9[\mathrm{~F}(2,376)=102.245, \mathrm{p}<.001$, effect size was large (eta squared $=0.35)]$, for question $10[\mathrm{~F}(2,370)=19.179, \mathrm{p}<.001$, effect size was medium (eta squared $=0.09)]$, for question $11[\mathrm{~F}(2$, $342)=44.877, \mathrm{p}<.001$, effect size was large $($ eta squared $=0.20)$ ], for question $12[\mathrm{~F}(2,377)=109.000, \mathrm{p}<.001$, effect size was large (eta squared $=0.36)]$, for question $13[\mathrm{~F}(2,378)=45.155, \mathrm{p}<.001$, effect size was large (eta squared $=0.19)]$, for question $14[\mathrm{~F}(2,373)$ $=45.155, \mathrm{p}<.001$, effect size was large (eta squared $=0.13)]$, for question $15[\mathrm{~F}(2,372)=93.631, \mathrm{p}<.001$, effect size was large (eta squared $=0.33)]$, and for question $16[\mathrm{~F}(2,378)=108.975, \mathrm{p}<.001$, effect size was large (eta squared $=0.36$ )]. Post-hoc comparisons using the Tukey HSD test indicated that laypeople had more negative attitudes regarding e-Health when compared to students and doctors (Table 1). In addition, the majority of the participants $(\mathrm{N}=307,79.32$ $\%)$ from all three groups reported in close-ended questions that they had no prior exposure to systematic programs, classes, seminars and/ or public lectures regarding e-Health, and they believed that such educational experiences only (without the need of real-life exposure) could change their personal attitudes $(\mathrm{N}=287,76.32 \%)$. 


\section{Discussion}

Present findings showed that still in Greece there are differences in the way that students, experts and the public receive and understand information regarding e-Health, but overall, negative attitudes are present. Thus, negative attitudes towards e-Health should be changed if we are to incorporate the benefits of its use in healthcare. More specifically, these findings from Greece regarding doctors' not clearly positive attitudes remind the problem that the effective utilization of e-Health tools may be possible only if healthcare professionals have positive attitudes towards e-Health. ${ }^{12}$ In this line, interventions should be made in education of future healthcare professionals, as well as in the continuing education of doctors through relevant knowledge dissemination that can take many forms.

\section{Conclusion}

Although e-Health is not a new concept in healthcare delivery in Greece, our respondents did not report fairly positive attitudes toward e-Health despite the attempts that have been made the last decade in Greece for the incorporation of e-Health and regardless of the multitude of structural and systemic difficulties. ${ }^{13,14}$ Although findings from small-scale experiments support that such negative attitudes can be changed with simple brief informative interventions in students, ${ }^{5}$ it still remains unexplored if social and psychological factors (other than education and age) can have an influence on attitudes towards e-Health. Based on our findings, future research should clarify the influence of a plethora of factors and incorporate them in education programs in order e-Health to be fully integrated in the healthcare system in Greece.

\section{Acknowledgments}

Research conducted with financing by "IKY Fellowships of Excellence for Postgraduate Studies in Greece-Siemens Program".

\section{Conflicts of interest}

Author declares there are no conflicts of interest.

\section{Funding}

None.

\section{References}

1. World Health Organization. eHealth, Switzerland. 2016.

2. Stellefson M, Hanik B, Chaney B, et al. eHealth literacy among college students: A systematic review with implications for eHealth education. Journal of Medical Internet Research. 2011;13(4):e102.
3. Stellefson M, Hanik B, Chaney JD, et al. Analysis of ehealth search perspectives among female college students in the health professions using Q methodology. J Med Internet Res. 2012;14(2):e60.

4. Dockweiler C, Hornberg C. Knowledge and attitudes as influencing factors for adopting health care technology among medical students in Germany. Journal of the International Society for Telemedicine and eHealth. 2014;2(1):64-70.

5. Lam MK, Nguyen M, Lowe R. I can do it: Does confidence and perceived ability in learning new ICT skills predict pre-service health professionals' attitudes towards engaging in e-healthcare? In $\mathrm{H}$. Grain, F. Martin-Sanchez \& L. K. Schaper (Eds.), Investing eHealth: People, knowledge, and technology for a healthy future. Amsterdam, Netherlands: IOS Press BV. 2014. p.60-66.

6. Giannouli V, Syrmos N. Is it easy to change attitudes towards e-health? A pilot experimental study in first-year students. Paper to be presented at the 17th International HL7 Interoperability Conference (IHIC) and eHealth, Greece "Re-shaping healthcare systems". 2017.

7. Arning K, Ziefle M, Arning J. Comparing apples and oranges? Exploring users' acceptance of ICT-and eHealth-applications. Digital Camera. 2008;83(50):1.

8. Currie M, Philip LJ, Roberts A. Attitudes towards the use and acceptance of eHealth technologies: A case study of older adults living with chronic pain and implications for rural healthcare. BMC Health Services Research. 2015;15(1):162.

9. Dutta-Bergman M. Trusted online sources of health information: Differences in demographics, health beliefs, and health-information orientation. J Med Internet Res. 2003;5(3):e21.

10. Hardiker NR, Grant MJ. Factors that influence public engagement with eHealth: A literature review. Int J Med Inform. 2011;80(1):1-12.

11. Ward R, Glogowska M Pollar K, Moule P. Developing and testing attitude scales around IT. Nurse Researcher. 2009;17(1):77-87.

12. Olok GT, Yagos WO, Ovuga E. Knowledge and attitudes of doctors towards e-health use in healthcare delivery in government and private hospitals in Northern Uganda: A cross-sectional study. BMC Medical Informatics and Decision Making. 2015;15(1):87.

13. Angelidis P, Giest S, Dumortier J, et al. Country brief: Greece. European Commission, DG Information Society and Media, ICT for Health Unit, Greece. 2010.

14. Fragidis LL, Chatzoglou PD. The use of electronic health record in Greece: current status. In Computer and Information Technology (CIT), 11th International Conference. IEEE, Cyprus, pp. 2011. p.475-480. 